\title{
Prevalence of Impacted Teeth among the Orthodontic Patient in Banga- bandhu Sheikh Mujib Medical University
}

\author{
Nahar L $^{1}$ BDS, FCPS, Jha $\mathrm{D}^{2}$ BDS and Hassan G $\mathrm{S}^{3}$ BDS, PhD
}

\begin{abstract}
Aim: This study was attempted to find out the prevalence of impacted teeth among the patients attended for orthodontic treatment in Bangabandhu Sheikh Mujib Medical University
\end{abstract}

Materials and Methods: For this cross sectional study 200 patients were taken according to selction criteria who were seeking orthodontic treatment, age between 10 and 30 years in Bangabandhu Sheikh Mujib Medical University.

Results: $42.0 \%$ respondents belong to age group 11-15 years, 65.5\% respondents were female and 34.5\% were male, who had impacted teeth with other orthodontics problems. Among 3.0\% respondents $1.5 \%$ showed impaction in right upper central incisor and other showed impaction in right upper canine, in left upper central incisor and also left upper canine. The prevalence of impacted teeth was not significant for age group ( $\mathrm{p}=0.449)$ and there was no significant difference between male and female $(\mathrm{p}=0.695)$.

Conclusion: The prevalence of tooth impaction is a common dental anomaly. The early recognition of tooth impaction is very important from a therapeutic point of view.

Key words: Prevalence, impaction.

\section{INTRODUCTION}

Dental impaction is defined as cessation of eruption of a tooth caused by a physical barrier in the eruption path or the abnormal position of the teeth., ${ }^{1,2}$ Apart from the eruption process, the successful development of permanent dentition involves the synchronized forward and lateral growth of both the maxilla and mandible, which compensates for the difference in size of the dentition in both bones. ${ }^{3}$ Impacted and ectopic teeth may lead to spacing in the arch and shifting of the midline if contra lateral tooth is erupted. ${ }^{4}$ They can cause migration of the neighboring teeth and loss of arch length, internal resorption; dentigerous cyst formation; external root resorption of the neighboring teeth, infection particularly with partial eruption and referred confusing pain. ${ }^{5}$

The prevalence of impacted maxillary canines is $0.9-2.2 \%$, but mandibular canine impaction occurs less frequently. ${ }^{6-8}$ Multiple impacted teeth by itself is a rare condition and often found in association with syndromes such as cleidocranial dysplasia, Gardner's syndrome, Down syndrome, Aarskog syndrome, Zimmerman-Laband syndrome and Noonan's syndrome. ${ }^{9}$

In Bangladesh a few studies have been conducted to observe the prevalence of impacted teeth in Bangladeshi population. This small scale study attempted to find out the prevalence of impacted teeth among the patients attended for orthodontic treatment in the department of Orthodontics and Dentofacial Orthopedics in Bangabandhu Sheikh Mujib Medical University (BSMMU).

\section{MATERIAS AND METHODS}

It is a descriptive cross sectional study conducted among the patients seeking orthodontic treatment in the outpatient department of Bangabandhu Sheikh Mujib Medical University. Patients between the age of 10 to 30 years were included. Third molars and patient with history of extraction of impacted teeth/tooth were excluded in this study.

Orthodontic files, which included history, clinical examination, orthopantomograms, study models, were the source of information used to diagnose impacted tooth. If an accurate diagnosis could not be made, the files were excluded from the study.

Descriptive analysis was performed with 95\% confidence interval. SPSS 17 was used for data analysis. 


\section{RESULT}

Out of 200 cases $35.5 \%$ were male and $65.5 \%$ were female. Majority of the cases were between the age of 10 to 15 years $(42 \%)$

Table- 1: Distribution of the respondents by impaction present or absent

\begin{tabular}{lcc}
\hline $\begin{array}{c}\text { Impaction present } \\
\text { or absent }\end{array}$ & Frequency & Percent \\
\hline Present & 6 & 3.0 \\
Absent & 194 & 97.0 \\
Total & 200 & 100.0 \\
\hline
\end{tabular}

Table 1 shows $3 \%$ respondent has impacted teeth

Table -2 : Distribution of the respondents by Impaction in which teeth

\begin{tabular}{lcc} 
Impaction (no. of teeth) & Frequency & Percent \\
\hline impaction in right upper 1 & \multicolumn{1}{c}{3} & 1.5 \\
impaction in right upper 3 & 1 & .5 \\
impaction in left upper 1 & 1 & .5 \\
impaction in left upper 3 & 1 & .5 \\
Total & 6 & 3.0 \\
Missing System & 194 & 97.0 \\
Total & 200 & 100.0
\end{tabular}

Table- 3: Comparison between male and female impaction present or absent

\begin{tabular}{llllllll} 
& present & \multicolumn{2}{c}{ Absent } & Total & p value \\
\hline male & 2 & $2.90 \%$ & 67 & $97.10 \%$ & 69 & $100 \%$ & \\
female & 4 & $3.15 \%$ & 127 & $96.85 \%$ & 131 & $100 \%$ & 0.695 \\
Total & 6 & $3 \%$ & 194 & $97 \%$ & 200 & $100 \%$ & \\
\hline
\end{tabular}

Table 3 shows impaction slightly more in female than male but not significant.
Table-4: Age of the patient impaction present or absent in Cross tabulation

\begin{tabular}{lcccc}
\hline $\begin{array}{l}\text { Age } \\
\text { of } \\
\text { patient }\end{array}$ & \multicolumn{2}{c}{$\begin{array}{l}\text { impaction present } \\
\text { or absent }\end{array}$} & Total & $\begin{array}{l}\text { Chi } \\
\text { square } \\
\text { test }\end{array}$ \\
\hline $11-15$ & 4 & 80 & 84 & \\
$16-20$ & 0 & 43 & 43 & \\
$21-25$ & 2 & 58 & 60 & 0.449 \\
$26-30$ & 0 & 13 & 13 & \\
Total & 6 & 194 & 200 & \\
\hline
\end{tabular}

Table 4 shows impaction more in 11-15 age group but not clinically significant

\section{DISCUSSION}

Impaction of teeth accounted for $2.95 \%$ prevalence in another research which is similar to our research. They examined 677 dental patient clinically and radiographically. ${ }^{1}$ The prevalence of impacted maxillary canines is $0.9-2.2 \%$, but mandibular canine impaction occurs less frequently. ${ }^{4,5} \mathrm{~A}$ cross sectional study was conducted in the outpatient department, Department of Orthodontics and Dentofacial Orthopedics, Dhaka Dental College and Hospital, Mirpur - 14, Dhaka, in between March 2005 to March 2008. In this study incidence of canine impaction involves approximately $2.8 \%$ of the patients seeking orthodontic treatment. ${ }^{10,11}$ The result is almost similar to our study except the mean age of the patient of impaction. A random sample of 580 panoramic radiographs was collected from the patients' record of a dental clinic in Dhaka city. Out of 580 panoramic radiographs it was found that impacted maxillary canines were present in only $7(1.2 \%)$ radiographs. ${ }^{12}$ The prevalence of impacted teeth in the study population of Hamadan dental school was $18 \%$. More than $30 \%$ of patients in this study were 22 and 30 years of age. In this study the prevalence of impacted teeth decreased with increasing age. ${ }^{13,14}$

\section{LIMITATIONS}

- Relatively small sample size was the main limitation.

- The study was carried out in BSMMU, Shahbag, Dhaka. As the study was conducted in a dental unit of a hospital it may not reveal the picture of the country. 


\section{CONCLUSION}

The prevalence of tooth impaction is a common dental anomaly. The early recognition of tooth impaction is very important from a therapeutic point of view. Impacted teeth result in many complications and their early detection is imperative. The results of this study were similar to the data reported in other studies, while the dissimilarities may be attributed to the sample selection, method of the study and area of patient selection, which suggest racial and genetic differences.

\section{REFERENCE}

1. Rageobar, G.M., G. Boering, A. Vissink and B. Stegenga, 1999. Eruption disturbances of permanent molars. A review.JOral Pathoj Med, 20(4): 159-166.

2. Fardi A.,Sidira A.K., Bachour Z.,Parisis N.,Tsirlis A. Incidence of Impacted \& Supernumerary Teeth- a radiographic study in a North Greek Population. Med Oral Patol Cir Bucal. 2011 Jan 1;16 (1):e56-61.

3. Otto R A. Early and unusual incisor resorption due to impacted maxillary canines. Am J Orthod Dentofacial Orthop 2003; 124:446-9.

4. Shafer WG, Hine MK, Levy BM.A text book of oral pathology.4th ed. Philadelphia: W B Saunders, 1984.need of orthodontic treatment in 10-year old children in Gothenburg. Swed Dent J 1972; 65:7-21.

5. D’Amico RM, Bjerklin K, Kurol J, Falahat B. Long-term Results of
Orthodontic Treatment of Impacted Maxillary Canines. Angle Orthod 2003: 73:231-238.

6. Aydin U, Yilmaz HH, Yildirim D. Incidence of canine impaction and transmigration in a patient population. Dentomaxillofac Radiol 2004: 33:164-9.

7. Alaejos-Algarra C, Berini-Aytes L, Gay-Escoda C. Transmigration of mandibular canines: Report of six cases and review of the literature. Quintessence Int. 1998: 29:395-398.

8. Gorlin RJ, Cohen MM, Hennekam RCM. Syndromes of the Head and Neck. Fourth. Oxford University Press; US: 2001.

9. Ghapanchi J.,Haghnegahder A.,Khodadadzadeh S.,Pourshahidi S.,Ebrahimi H. Prevalence of taurodontism , missing \& impacted teeth In South of Iranian Population .Aust .J.Basic \& Appl. Sci. 5(9): 430-434,2011.

10. Moyer RE .Hand book of orthodontic. 4th ed. Chicago: Year Book Medical Publishers, 1988.ch-15. P-386-387.

11. Khan N. Clinical and radiological evaluation of maxillary canine after autotransplantation [dissertation]. Karachi:College of physicians \& surgeons Pakistan, 2003.

12. Alam M. M., Hossain M. Z. Incidence of Impacted Permanent Canines and Its Orthodontic Management. Vol-23. 2007. No1-2.

13. Alif S.M., Sejuty H., Nimmi N., Ashraf A., Khan S.H. \& Khan M.H. Panoramic radiological study to identify locally displaced maxillary canines in Bangladeshi population. Imaging Sci Dent. 2011 December; 41(4): 155-159.

14. Pursafar, F. Salemi, F.Dalband, M. Khamverdi, Z. Prevalence of Impacted Teeth and Their Radiographic Signs in Panoramic Radiographs of Patients Referred to Hamadan Dental School in 2009. DJH 2011; Vol.2, No.2

\section{Correspondence}

Dr. Lutfun Nahar Lata BDS, FCPS

Assistant Professor

Dept. of Orthodontics

University Dental College and Hospital

Mob: +88 01199063643

E-mail: latan@yahoo.com 